University of Wollongong

Research Online

Faculty of Engineering and Information

Faculty of Engineering and Information

Sciences - Papers: Part B

Sciences

2017

Identifying the wheeling costs associated with solar sharing in LV distribution networks in Australia using power flow tracing and MW-Mile methodology

Bosui Li

University of Wollongong, bl950@uowmail.edu.au

Duane A. Robinson

University of Wollongong, duane@uow.edu.au

Ashish P. Agalgaonkar

University of Wollongong, ashish@uow.edu.au

Follow this and additional works at: https://ro.uow.edu.au/eispapers1

Part of the Engineering Commons, and the Science and Technology Studies Commons

Research Online is the open access institutional repository for the University of Wollongong. For further information contact the UOW Library: research-pubs@uow.edu.au 


\title{
Identifying the wheeling costs associated with solar sharing in LV distribution networks in Australia using power flow tracing and MW-Mile methodology
}

\author{
Abstract \\ PV systems, as one type of distributed generation, have been popularly applied to residential and \\ commercial power supply systems for compensating grid electricity consumption. Schemes for sharing \\ PV power within LV distribution networks have also begun to develop, with the aim to more widely spread \\ the benefits of utilizing localized renewable-generated electricity. Consequently, to utilize the local LV \\ distribution network, there is an argument that customers (both small scale generators and consumers) \\ should pay a 'wheeling charge' to utilities for grid services related to the transport of energy, similar to \\ their transmission counterparts. This paper presents some of the existing issues related to implementing \\ a 'wheeling charge' for network services raised in the process of sharing locally generated PV power in a \\ LV distribution system. Two methodologies: 'generation matrix', based on proportional sharing principle; \\ and 'MW-Mile', based on network losses, have been combined to cover the economic operation and \\ tracing of energy supplied by a PV generator and transported through the local LV distribution network. An \\ evaluation of the potential costs of using the LV distribution network including daily PV output and \\ building load demand is provided, utilising a case study. \\ Disciplines \\ Engineering | Science and Technology Studies

\section{Publication Details} \\ B. Li, D. A. Robinson \& A. Agalgaonkar, "Identifying the wheeling costs associated with solar sharing in LV \\ distribution networks in Australia using power flow tracing and MW-Mile methodology," in 2017 \\ Australasian Universities Power Engineering Conference (AUPEC), 2017, pp. 1-6.
}




\title{
Identifying the Wheeling Costs Associated with Solar Sharing in LV Distribution Networks in Australia using Power Flow Tracing and MW-Mile Methodology
}

\author{
Bosui Li, Duane A. Robinson, Ashish Agalgaonkar \\ Australian Power Quality and Reliability Centre \\ School of Electrical, Computer and Telecommunications Engineering \\ University of Wollongong, NSW, Australia \\ b1950@uowmail.edu.au
}

\begin{abstract}
PV systems, as one type of distributed generation, have been popularly applied to residential and commercial power supply systems for compensating grid electricity consumption. Schemes for sharing PV power within LV distribution networks have also begun to develop, with the aim to more widely spread the benefits of utilizing localized renewable-generated electricity. Consequently, to utilize the local $\mathrm{LV}$ distribution network, there is an argument that customers (both small scale generators and consumers) should pay a 'wheeling charge' to utilities for grid services related to the transport of energy, similar to their transmission counterparts.

This paper presents some of the existing issues related to implementing a 'wheeling charge' for network services raised in the process of sharing locally generated PV power in a LV distribution system. Two methodologies: 'generation matrix', based on proportional sharing principle; and 'MW-Mile', based on network losses, have been combined to cover the economic operation and tracing of energy supplied by a PV generator and transported through the local $L V$ distribution network. An evaluation of the potential costs of using the LV distribution network including daily PV output and building load demand is provided, utilising a case study.
\end{abstract}

Index Terms- MW-Mile, power flow tracing, PV systems, solar sharing, wheeling costs.

\section{INTRODUCTION}

In transmission systems, wheeling costs associated with transporting power from one party to another in a deregulated electricity market is generally counted in the full selling rate of grid power [1]. A wheeling charge could also be raised for using low voltage (LV) networks to transport power for customers (both small scale generators and consumers) involved in solar PV power sharing schemes. Although, there is an argument that such charges unduly disincentivise LV customers for sharing PV power, as outlined in $[2,3]$.

PV power sharing schemes and tariffs include virtual net metering (VNM) [2]. In USA, for implementation of VNM, one of the existing rules is that a local generator and all the beneficiary accounts must be connected behind a single distribution service point (DSP) of the network [3]. In some Australian states, there remain legal barriers which inhibit setting up a single DSP (behind the meter operation) for multiple customers. Limiting such schemes to a single DSP however will no doubt be adjusted in the near future given the extent of larger PV systems being installed within LV networks and consumers looking to maximise the cost benefit of their investment. Accordingly, a study to determine suitable wheeling costs associated with solar PV sharing, potentially crossing multi-DSPs, is required.

This paper will demonstrate solar PV power sharing crossing multi-DSPs while applying typical daily profiles of PV system output matched against building demand. The MW-Mile method is adopted for the economic evaluation of wheeling cost [4-6], and 'generation matrix' method is used to identify the contributions of multi-generators, where applicable [7]. This paper combines these two methodologies to evaluate the potential wheeling costs associated with using LV distribution systems to share PV power. Section II introduces the MW-Mile methodology and presents its application for the evaluation of the wheeling cost involved in LV network solar PV power sharing. Section III introduces the 'generation matrix' method that was developed based on proportional principle for tracing power contributed by multiple generators. A case study using nominal building demand and PV generation daily profiles are presented in Section IV, demonstrating an example implementation for the combined methods in a typical LV distribution network. Section V presents and discusses the results achieved by conducting the case study. The conclusions are presented in Section VI. 


\section{MW-MILE METHOD FOR EVALUATING WHEELING CHARGES}

There are several methodologies for the calculation of wheeling charges raised by transmission and distribution of grid electricity, e.g. post-stage stamp, path contract, MWMile, and marginal cost [10-11]. The methodologies value wheeling costs from different viewpoints involving technical and economic issues. This study applies 'MW-Mile' method to evaluate the correlation of wheeling cost and the extent of utilising grid, including the distance shared by passing power and the amount of wheeled power, which are key factors to assess wheeling costs $[8,9]$. Note that only active power is considered by this study for simplified evaluation.

In terms of 'MW-Mile', there are various expressions shown in previous studies [4-6, 12], but quantifying wheeledpower and wheeling distance are the two critical factors. Some adaptations of the 'MW-Mile' definitions are presented as followings, from [4]:

$$
T C_{t}=T C * \frac{\sum_{k \in K} C_{k} * L_{k} * P_{t k}}{\sum_{t \in T} \sum_{k \in K} C_{k} * L_{k} * P_{t k}}
$$

where $t$ is network user set, $k$ is the distribution line set, $T C_{t}$ is wheeling cost allocation of user $t$ in $\$ / \mathrm{MW}, T C$ is the total transmission cost in $\$ / \mathrm{MW}, C_{k}$ is the cost per MW per unit length of line $k$ in $\$ / \mathrm{MW}-\mathrm{km}, L_{k}$ is the length of distribution line $k$, and $P_{t k}$ stands for the power flow contributed by user $t$ in line $k$. Also, from [5]:

$$
C_{C T}=C * \frac{\sum_{f}\left(M W_{f}\right)_{T} * L_{f}}{\sum_{T} \sum_{f}\left(M W_{f}\right)_{T} * L_{f}}
$$

where $T$ is network user set, as above, $f$ is line branch of a network set, $C_{c t}$ is the network charge for user $T$ in $\$ / \mathrm{h}, C$ is total annual revenue requirement per hour in $\$ / \mathrm{h}, M W_{f}$ is the power flow in line branch $f$ due to the user $T$, and $L_{f}$ is the length of the network branch $f$. From [6]:

$$
T C_{n}=\sum_{i=1}^{l} \frac{C_{i} * L_{i} * P_{i n}}{p_{i}^{c}}
$$

where $n$ is user set and $i$ is transmission line set, $l$ represents the $l^{\text {th }}$ line. $T C_{n}$ is the transmission cost to network user $n$ in $\$ / \mathrm{MW}$ (MVA), $C_{i}$ is the cost per MW per unit length of line $i$ in $\$ / \mathrm{MW}$ (MVA)-km, $L_{i}$ stands for the length of transmission line $i, P_{i n}$ is power flow contributed by user $n$ in line $i$, and $p^{c}{ }_{i}$ is the power capacity of line $i$ in MW. From [12]:

$$
R_{k l}=\sum_{l=1}^{n} C_{f} * \frac{P_{k l}}{\sum_{k} P_{k l}}
$$

where $l$ is component line set, $n$ represents the $n^{\text {th }}$ line, $k$ is the network user set, $R_{k l}$ is the wheeling charge allocation to user $k$ in $\$ / \mathrm{h}, P_{k l}$ is power flow contributed by user $k$ in line $l$, $C_{f}$ is the total annual revenue requirement per hour for a feeder in $\$ / \mathrm{h}$ based on an expected payback period.

It can be seen in (1)-(4) that the expression can be divided into two components:

(i) Economic factors $-T C, C, C_{i}$, and $C_{f}$, representing total transmission cost as shown in (1) and (3) or expected annual revenue shown in (2) and (4); and (ii) Technical factors - the magnitude of related power and distance across network.

In this study, the shared PV power would pass through related feeders one after the other based on the radial nature of typical Australian LV distribution networks, so the accumulation of wheeling cost for each related feeder is a reasonable approach to evaluating the full wheeling cost under the scenario considered in this study. In addition, for simplified evaluation of financial assessment, this study calculates the cost applied to each feeder using $C_{f}$ as shown in (4). Therefore, (4) is adopted for the relevant calculations in each case study. Note that the wheeling cost evaluated by this study only considers the fixed investment of a network and neglects power loss, administrative fees, etc. This leads to a requirement to include an additional component to the MWMile method.

\section{GENERATION MATRIX FOR TRACING POWER FLOW}

From (4), $\sum_{i} P_{k l}$ is the power flow contributed by user $k$ in line $l$, and $\sum_{k} \sum_{i} P_{k l}$ is the total power flow in line $l$, so the identification of the power injected by a certain generator is a key point for the calculation of wheeling cost [13-16]. From the review of relevant research studies, there have been some methodologies developed to trace power flow within transmission networks [7, 17-18], and equally applicable to radial distribution networks. A review of these studies highlighted that each methodology was based on a common assumption of the proportional principle [19]. Electrons cannot be coloured or tagged to identify their source, and accordingly, the proportional principle is a reasonable treatment for addressing this issue [20, 21], and it can be demonstrated diagrammatically in Fig. 1.

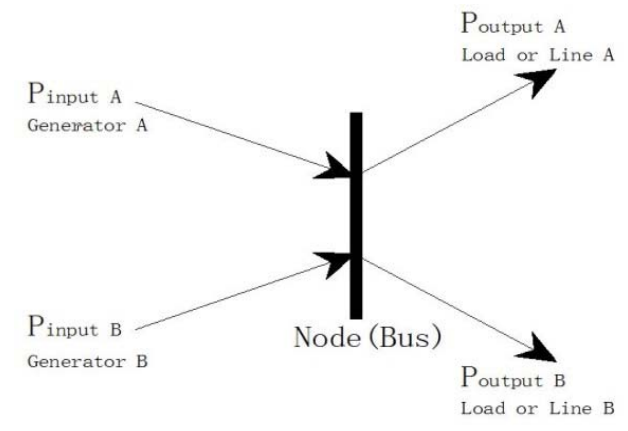

Fig. 1. Proportional sharing principle

Using Fig. 1, each bus output can be shown as being made up of proportional contributions from the individual bus inputs as per (5) and (6) [16].

$$
P_{\text {output } A}=P_{\text {output } A} *\left(\frac{P_{\text {input } A}}{P_{\text {input } A}+P_{\text {input } B}}+\frac{P_{\text {input } B}}{P_{\text {input } A}+P_{\text {input } B}}\right)
$$

$$
P_{\text {output } B}=P_{\text {outputB }} *\left(\frac{P_{\text {input } A}}{P_{\text {input } A}+P_{\text {input } B}}+\frac{P_{\text {input } B}}{P_{\text {input } A}+P_{\text {input } B}}\right)
$$

In this study, $\quad P_{\text {inputA }}\left(\left(P_{\text {input } A}+P_{\text {input } B}\right) \quad\right.$ and $P_{\text {inputB }} /\left(P_{\text {input } A}+P_{\text {input }}\right)$ are the 'tracing factors' hereunto notated 
as $T_{f}$. For clear and concise evaluation of power flow tracing, this study applies the 'generation matrix' to investigate the contributions from distributed PV systems and LV distribution network. For this method, the generator matrix is given by (7) and the node (or bus) matrix is given by (8).

$$
\begin{aligned}
& a_{1} \\
& \begin{aligned}
M_{g}= & \ldots \\
& a_{i}
\end{aligned} \\
& M_{b}=\begin{array}{l}
b_{1} \\
\ldots \\
b_{i}
\end{array}
\end{aligned}
$$

Where $i$ is generator set including MV/LV network bulk supply points and DG. Assuming the generator 1 is the network bulk supply point, and the generator $i$ is a shared PV system, the individual generator matrixes can be expressed as the follows:

$$
M_{g 1-\text { grid }}=\left[\begin{array}{c}
1 \\
0 \\
\ldots \\
0
\end{array}\right], M_{g i-p v}=\left[\begin{array}{c}
0 \\
0 \\
\ldots \\
1
\end{array}\right]
$$

In addition, for clear evaluation, this study categorizes nodes (buses) into 'source nodes' notated as $M_{b s}$ with load and generator and 'load node' notated as $M_{b b}$ for load only, in order to determine upstream and downstream power flow. The node matrix can be presented as follows:

$$
\begin{aligned}
& M_{b s k}=T_{f 1} * M_{g 1-g r i d}+T_{f 2} * M_{g 2}+T_{f i} * M_{g i-p v} \\
& =\left[\begin{array}{c}
b_{1}=T_{f 1} * 1 \\
b_{2}=T_{f 2} * 0 \\
\cdots \\
b_{i}=T_{f i} * 1
\end{array}\right] \\
& M_{b b(k 1)-(k n)}=M_{b s k}
\end{aligned}
$$

Where $k$ is source node (bus) set, $T_{f}$ is the tracing factor as described by (5) and (6), and the node ' $b s k$ ' is the upstream source node closest to the load node ' $b b(k 1)$ '. 'Upstream' indicates the direction towards power resource, which includes pole transformer and distributed PV systems in this study. Based on (11), it can be shown that the contributions at a source node $M_{b s k}$ would be carried by all the downstream load nodes, as $M_{b b(k l)} \sim M_{b b(k n)}=M_{b s k}$, until the next source bus $M_{b s(k+1)}$. In addition, $b_{i}$ is the contribution of the individual generator at a certain source node. Using (10) and (11) the contributions of all generators at overall nodes of a studied network can be solved.

So far, two methodologies were detailed for calculating wheeling cost and tracing power flow. In addition, based on (5) and (6), it can be understood that $b_{i}$ shown in (10) is the ratio of $P_{k l} / \Sigma_{k} P_{k l}$ as shown in (4), provided the fixed cost of each feeder of a LV distribution network $C_{f}$ is assumed fixed. In such case, the wheeling cost can be presented by (4).

\section{CASE STUDY OF SHARING PV POWER IN A RESIDENTIAL PRECINCT}

This study establishes a MV/LV distribution network for detailed calculations by referring to a segment of $\mathrm{MV} / \mathrm{LV}$ distribution system in Wollongong City, which is represented by Fig. 2 below.

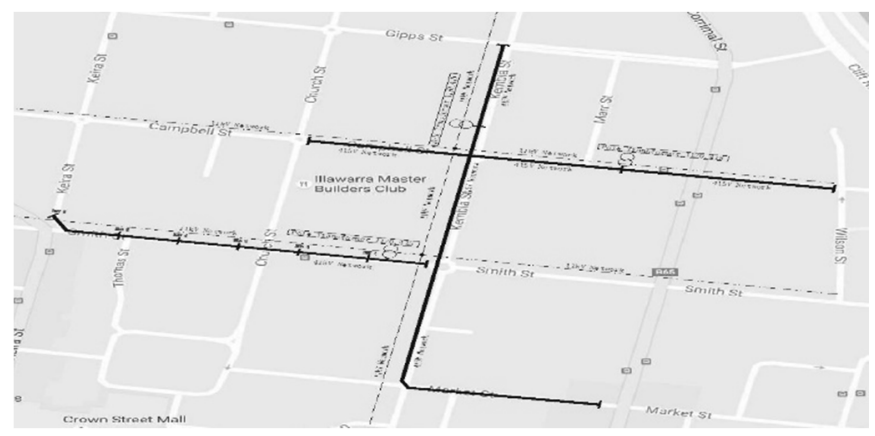

Fig. 2. Map of a part of $11 \mathrm{kV}$ and LV residential distribution networks in Wollongong City [22]

In Fig. 2, the dashed lines represent segments of local $11 \mathrm{kV}$ networks, and the solid lines illustrate LV distribution feeders. Three pole transformers were marked to show the power supply boundary of the illustrated segments. The distribution feeder with the length of around $0.5 \mathrm{~km}$ serving

\begin{tabular}{|c|c|c|c|c|c|c|c|c|}
\hline Item & \multicolumn{8}{|c|}{ Values } \\
\hline $\begin{array}{l}\text { Capacity of Pole } \\
\text { transformer (kVA) }\end{array}$ & \multicolumn{8}{|c|}{$160(11 \mathrm{kV} / 0.415 \mathrm{kV})$} \\
\hline $\begin{array}{l}\text { Rated capacity of } \\
\text { PV systems }(\mathrm{kW})\end{array}$ & \multicolumn{8}{|c|}{100} \\
\hline \multirow{2}{*}{$\begin{array}{l}\text { Consumer peak } \\
\text { load demand }(\mathrm{kW})\end{array}$} & Load1 & Load2 & Load3 & Load4 & Load5 & Load6 & Load7 & Load8 \\
\hline & 5 & 25 & 5 & 5 & 10 & 25 & 20 & 5 \\
\hline \multirow{2}{*}{$\begin{array}{l}\text { Location of bus } \\
\text { (distance from bus } \\
\text { to pole transformer } \\
(\mathrm{km})\end{array}$} & Bus1 & Bus2 & Bus3 & Bus4 & Bus5 & Bus6 & & \\
\hline & 0 & 0.1 & 0.2 & 0.3 & 0.4 & 0.5 & & \\
\hline \multirow{2}{*}{$\begin{array}{l}\text { Distribution line } \\
\text { length }(\mathrm{km})\end{array}$} & Line1 & Line2 & Line3 & Line4 & Line5 & & & \\
\hline & 0.1 & 0.1 & 0.1 & 0.1 & 0.1 & & & \\
\hline
\end{tabular}
the western part of the street was used for this study. For simplified calculation and analyses, it was assumed that there are six buses (nodes) and every two neighbouring buses have equal spacing distance. The assumptions for further calculations are presented in Table I.

\section{TABLE I. Relevant assumptions}

The total load demand capacity of $100 \mathrm{~kW}$ is satisfied to the acceptable voltage drop of $6 \%$ of the rated voltage of a LV distribution system in Australia [23].

This study considers the daily profiles of PV generation and building load demand to evaluate the related impacts on wheeling costs. The assumed $\mathrm{kW}$ peak rating of the shared solar system is $100 \mathrm{~kW}$, and the changing hourly PV generation is presented in Table II (non-generation times of 8:00pm - 6:00am excluded).

\section{TABLE II. Daily changing PV generation}

\begin{tabular}{|l|c|c|c|c|c|c|c|c|c|c|c|c|c|}
\hline Time (h) & 7 & 8 & 9 & 10 & 11 & 12 & 13 & 14 & 15 & 16 & 17 & 18 & 19 \\
\hline $\begin{array}{l}\text { PV } \\
\text { generation } \\
\text { (kW) }\end{array}$ & 0 & 22 & 46 & 68 & 84 & 96 & 100 & 97 & 89 & 72 & 51 & 30 & 0 \\
\hline
\end{tabular}

Two categories of building profiles were applied, and each assumed load capacity was multiplied by the ratios shown in Tables III and IV to calculate the exact hourly load demands. 
Note that the time period was from 7:00am to 7:00pm to coincide with a typical sunny day with generation available during the same hours for the PV systems. The case study LV distribution network model is presented in Fig. 3.

TABLE III. Daily load demand of residential building

\begin{tabular}{|l|c|c|c|c|c|c|c|c|c|c|c|c|c|}
\hline $\begin{array}{l}\text { Time } \\
\text { (h) }\end{array}$ & 7 & 8 & 9 & 10 & 11 & 12 & 13 & 14 & 15 & 16 & 17 & 18 & 19 \\
\hline $\begin{array}{l}\text { Building } \\
\text { demand } \\
\text { (per } \\
\text { unit) }\end{array}$ & 0.62 & 0.59 & 0.55 & 0.51 & 0.52 & 0.54 & 0.55 & 0.57 & 0.60 & 0.74 & 0.89 & 0.98 & 1 \\
\hline
\end{tabular}

TABLE IV. Daily load demand of office building

\begin{tabular}{|l|c|c|c|c|c|c|c|c|c|c|c|c|c|}
\hline $\begin{array}{l}\text { Time } \\
\text { (h) }\end{array}$ & 7 & 8 & 9 & 10 & 11 & 12 & 13 & 14 & 15 & 16 & 17 & 18 & 19 \\
\hline $\begin{array}{l}\text { Building } \\
\text { demand } \\
\text { (per } \\
\text { unit) }\end{array}$ & 0.67 & 0.88 & 0.98 & 0.96 & 0.96 & 0.95 & 0.97 & 0.97 & 0.97 & 1 & 0.97 & 0.83 & 0.77 \\
\hline
\end{tabular}

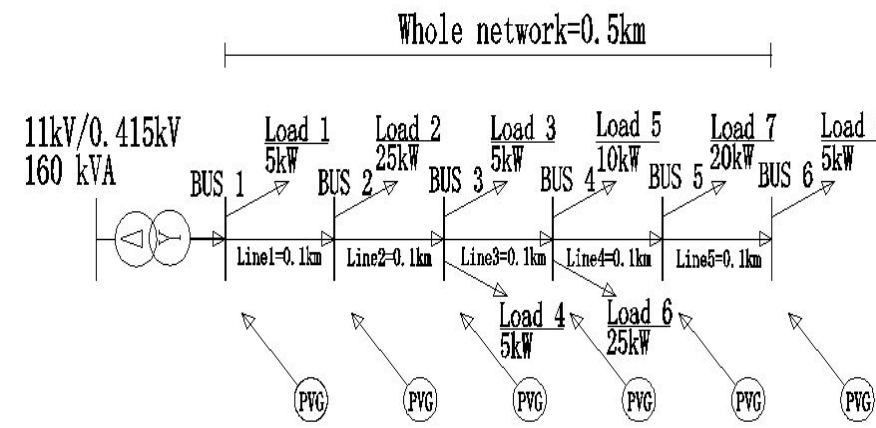

Fig. 3. LV distribution network model

TABLE V. Financial assumptions and calculated results

\begin{tabular}{|c|c|c|c|}
\hline Items & $\begin{array}{c}\text { Assumed } \\
\text { values }\end{array}$ & $\begin{array}{c}\text { Calculated } \\
\text { results }\end{array}$ & \multicolumn{1}{|c|}{ Remarks } \\
\hline $\begin{array}{c}\text { Total cost of 0.5 } \\
\text { km LV distribution } \\
\text { lines - PV }\end{array}$ & $\$ 143,935$ & $\begin{array}{l}\text { Including cable } 500 \mathrm{~m}\left(95 \mathrm{~m}^{2}\right), 20 \\
\text { wooden poles, and insulator string } \\
(5 \% \text { cable cost })\end{array}$ \\
\hline$C$ & $3 \%$ & $\$ 217,794$ & $\begin{array}{l}1.3 \% \sim 4.5 \% \text { in recent } 15 \text { years in } \\
\text { Australia context }\end{array}$ \\
\hline$i$ & $5 \%$ & $\begin{array}{l}1.5 \% \sim 7.25 \% \text { in recent } 15 \text { years in } \\
\text { Australia context }\end{array}$ \\
\hline$d$ & 20 years & $\begin{array}{l}\text { Referring to the normal solar PV } \\
\text { lifespan of 25 years }\end{array}$ \\
\hline$n$ & & $\$ 0.2486 / \mathrm{h}$ & Each feeder \\
\hline$C_{f}$ & &
\end{tabular}

The proposed research study assumes only a single solar PV system, labelled PVG, connected to the network in Fig. 3 for sharing solar power. In Fig. 3, the six alternative locations of PVG are marked along the feeder, connected to Bus 1 to Bus 6, to evaluate the potential impacts of installation location of the solar PV system on wheeling cost. In addition, Bus 4 has two different loads as load $5(10 \mathrm{~kW})$ and load $6(25 \mathrm{~kW})$ as shown in Fig. 3, so the net PV power injected to the network will be different when the shared PV system is respectively connected to loads at Buses 5 and 6 . Therefore, for the shared PV system there are two different locations at Bus 4 notated as B4 and B4(a), so the whole network has total of seven locations for installing the shared solar PV system.
The related economic assumptions and the calculated result of fixed investment of each feeder are presented in Table V. Where, $C$ is any cost element at $n^{\text {th }}$ year, $i$ is the inflation rate, $d$ is the discount rate/interest rate, $n$ is the expected payback years, and $C_{f}$ is the annual revenue requirement per hour for a distribution feeder in $\$ / \mathrm{h}$ based on an expected payback period.

\section{RESULTS AND DISCUSSION}

\section{A. Results}

Based on the above assumptions and calculated results, the wheeling cost can be evaluated by (4), (10) and (11). In addition, two study scenarios were set as static condition and dynamic condition. In Scenario 1 (static condition), overall eight loads take peak values shown in Tables III and IV, and six PV outputs as $22 \mathrm{~kW}, 30 \mathrm{~kW}, 52 \mathrm{~kW}, 72 \mathrm{~kW}, 89 \mathrm{~kW}$, $100 \mathrm{~kW}$ are selected from Table II and studied independently. In Scenario 2 (dynamic condition), PV outputs and all load demands are time-varying by applying the daily profiles of $\mathrm{PV}$ generation and residential building load demand shown in Tables II and III. Again, the impact of shared PV system was studied individually connecting to the six bus locations. Additional assumptions and notations for the simulation case study scenarios are presented in Table VI.

\section{TABLE VI. Notations of testing parameters}

\begin{tabular}{|c|c|c|}
\hline \multicolumn{2}{|c|}{ Items } & Notation \\
\hline \multicolumn{2}{|c|}{ D from PT $(\mathrm{km})$} & $\begin{array}{l}\text { Distance from each bus to the pole transformer } \\
\text { listed on Table1 }\end{array}$ \\
\hline \multicolumn{2}{|c|}{ D down passing $(\mathrm{km})$} & $\begin{array}{l}\text { Distance the shared power passing towards the } \\
\text { loads direction }\end{array}$ \\
\hline \multicolumn{2}{|c|}{$\mathrm{D}$ up passing $(\mathrm{km})$} & $\begin{array}{l}\text { Distance the shared power passing towards the } \\
\text { pole transformer direction }\end{array}$ \\
\hline \multirow{2}{*}{$\begin{array}{l}\text { Assessment } \\
\text { approach } \\
\text { MW-Mile }\end{array}$} & $\begin{array}{c}\mathrm{WC} \\
(\$ / \mathrm{kWh})\end{array}$ & $\begin{array}{l}\text { Wheeling cost caused by distributing solar power } \\
\text { in } \$ \text { per kilowatt hour }\end{array}$ \\
\hline & $\begin{array}{l}\mathrm{WC} \\
(\$ / h)\end{array}$ & $\begin{array}{l}\text { Wheeling cost caused by distributing solar power } \\
\text { in } \$ \text { per one hour }\end{array}$ \\
\hline \multicolumn{2}{|c|}{ Sharing percentage $\%$} & $\begin{array}{l}\text { The ratio of net PV power exported from a node } \\
\text { over total power supply (the sum of PV power } \\
\text { and grid power) }\end{array}$ \\
\hline \multicolumn{2}{|c|}{ Wheeled power $(\mathrm{kW})$} & $\begin{array}{l}\text { The amount of wheeled net PV power (hourly PV } \\
\text { output minor all loads connecting to the common } \\
\text { bus) }\end{array}$ \\
\hline
\end{tabular}

Note that there are two components/types of wheeling costs, each with different units, i.e. $\$ / \mathrm{kWh}$ and $\$ / \mathrm{h}$. Based on (4), the calculated result should be in $\$ / h$. To evaluate wheeling cost from a different viewpoint, this result is assigned to per $\mathrm{kW}$ of wheeled solar power in $\$ / \mathrm{kWh}$. The results evaluated under two scenarios are depicted in Figs. 4 and 5. All items shown in Table VI were evaluated under the two different scenarios.

For a comprehensive understanding about the potential impacts on wheeling costs from the profile of building load demand, 'B4' is tested by applying the PV system to a large office load profile instead of a residential building profile. The comparative results are presented in Fig. 6. 


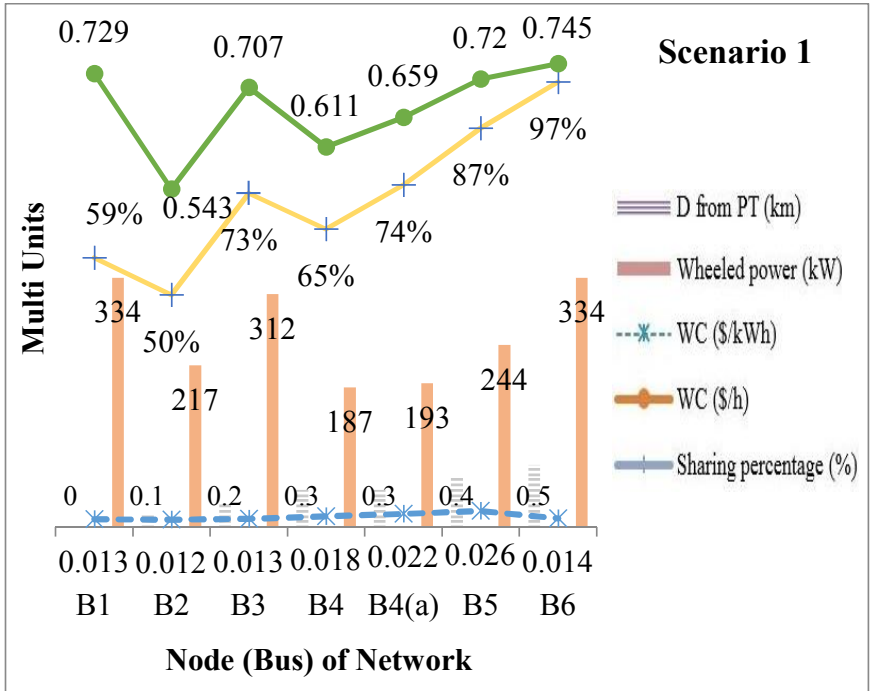

Fig. 4. Results under Scenario 1

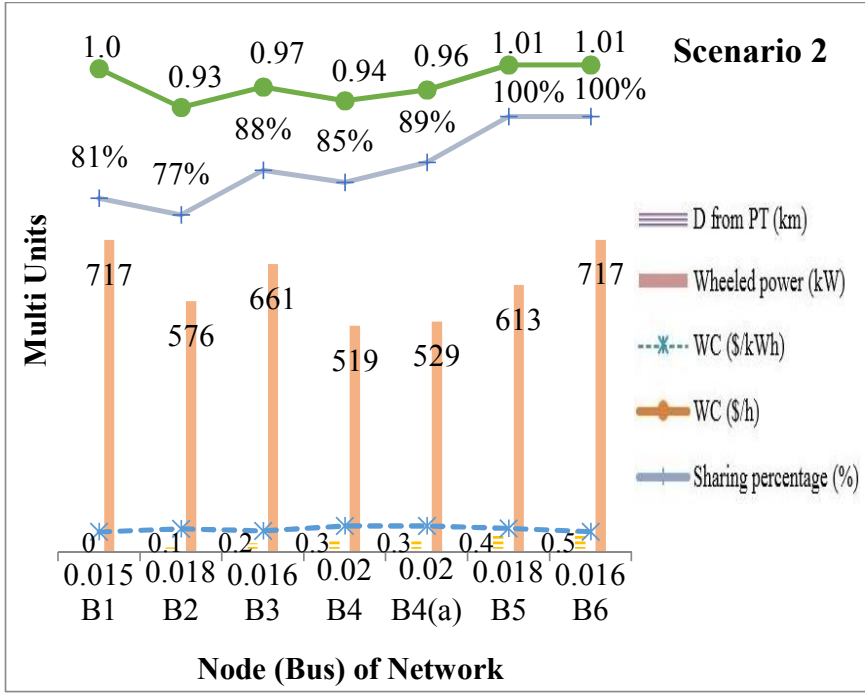

Fig. 5. Results under Scenario 2

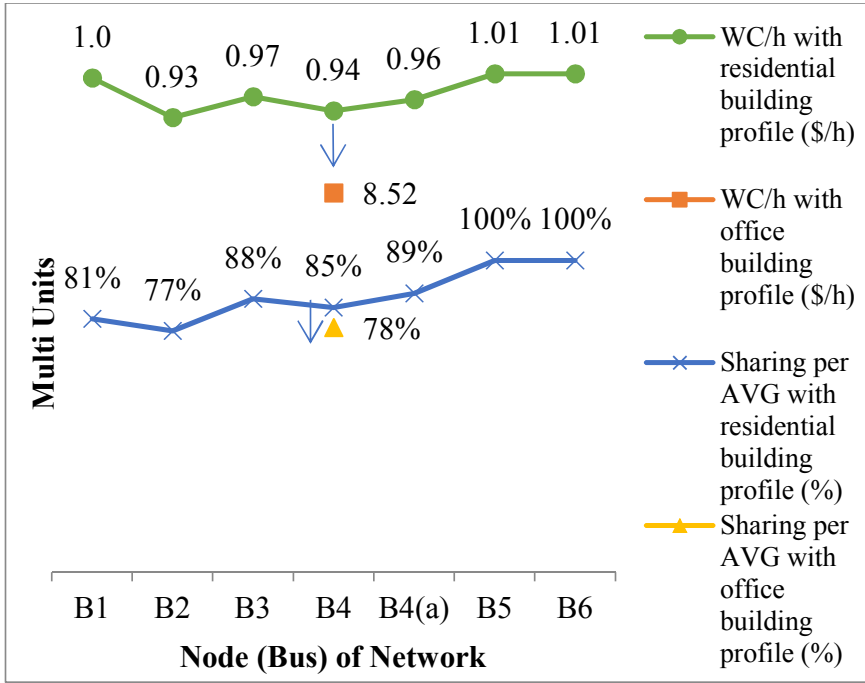

Fig. 6. Comparison of results considering two different building load profiles

\section{B. Analysis}

From Figs. 4 and 5, it is demonstrated that the wheeling cost for sharing PV power is not in direct proportion to the extent of utilising grid (considering the distance and amount of wheeled solar power), and there is not a distinct rule between wheeling cost and the extent of using grid. By contrast, the curves of sharing percentage and wheeling costs ('WC $\$ / h$ ') have almost the same profiles. Note that several data points of sharing percentage have, however, different scenarios by further comparison. For example, Bus 1 has a higher ' $\mathrm{WC} \$ / \mathrm{h}$ ' at $0.729 \$ / \mathrm{h}$, but with lower sharing percentage $59 \%$ than Bus 3 , with $0.707 \$ / \mathrm{h}$, and a sharing percentage of $73 \%$, as illustrated in Fig. 4. The same situation exists for Bus 4 and Bus 4(a) in Figs. 4 and 5. From a further comparison of results, it can be seen that the wheeling distance is the factor causing the mismatch between ' $\mathrm{WC} \$ / \mathrm{h}$ ' and sharing percentage. The results produced for Bus 1 as having a lower sharing percentage than Bus 3, Bus 4 and Bus 4(a), but the wheeling distance at Bus 1 is $0.5 \mathrm{~km}$ longer than other three buses. Note that the sharing percentage has more significant impact on wheeling cost than wheeling distance based on this comparison. According to the above analyses, this study proposes the combination of sharing percentage and wheeling distance as a reliable indicator to assist in establishing and evaluating wheeling costs for utilising LV distribution systems to share PV power.

This study tested two types of wheeling costs respectively shown by 'WC $\$ / \mathrm{h}$ ' and ' $\mathrm{WC} \$ / \mathrm{kWh}$ '. It is demonstrated that two types of wheeling costs at a same location of the shared PV system have different results in terms of values. It is to be noted that 'WC $\$ / \mathrm{kWh}$ ' is a value allocated to per $\mathrm{kW}$ based on 'WC $\$ / h$ ', so the quantity of $\mathrm{kW}$ of transmitted PV power is the critical factor which causes different results for the two types of wheeling costs.

Considering ' $\mathrm{WC} \$ / \mathrm{h}$ ', Bus 2 is the best location for installing the shared solar system for this case study, which is based on Bus 2 always having the lowest wheeling cost (WC $\$ / \mathrm{h}$ ), as illustrated in Figs. 4 and 5. For 'WC $\$ / \mathrm{kWh}$ ', Bus 1 is the best location for Scenario 1, as shown in Fig. 5, and Bus 1 and 2 have the similar situation as the value of $0.013 \$ / \mathrm{kWh}$ at Bus 1 compared to $0.012 \$ / \mathrm{kWh}$ at Bus 2, as shown in Fig. 4.

The shared solar power can be either reflected by rollingover credits such as VNM or actual power. This study distinguishes these two methods as credit-based and powerbased, respectively. For a credit-based solar sharing scheme, wheeling cost in $\$ / \mathrm{h}$ can directly indicate the desired install location without the consideration of actual exported power. In contrast, 'WC $\$ / \mathrm{kWh}$ ' varies depending on the substantial solar power fed into to the network, so for power-based sharing solar scheme, both exported $\mathrm{kW}$ power and wheeling cost need to be considered. This evaluation implies the method of the allocation of wheeling cost to each customer depending on different types of sharing solar scheme (credit-based and power-based) is another critical factor for the site-specific evaluation of wheeling cost.

From Fig. 6, both wheeling cost and sharing percentage with office-building load profile are lower than those for the 
residential building profiles at Bus 4 , and the reduction of wheeling cost is significant by Bus 4 replacing Bus 2 as the location with the lowest wheeling cost. This result can be explained by the proportion of daily load consumption, as office buildings depict higher shoulder and peak load consumption than the residential building respectively, and office building has a higher incidence of consuming PV generation. Hence, it locally consumes more PV generation than the residential building, and causes less $\mathrm{kW}$ of solar power to be wheeled, so sharing percentage drops and consequently wheeling costs are reduced. This comparison shows that building load profile can significantly vary the wheeling costs. Further studies testing more categories of buildings are needed to comprehensively evaluate the associated impact on wheeling costs.

\section{CONCLUSION}

This paper combines two methods, 'generation matrix' and 'MW-Mile' in order to study potential wheeling costs associated with solar sharing in LV distribution networks. The generation matrix is modified to adapt the feature of radial structure of $\mathrm{LV}$ distribution networks for studying relevant issues relating to wheeling charges.

This paper introduces time varying profiles of daily PV generation and load demands of residential and large-office building to study the potential impacts on wheeling costs. Due to the variations in daily PV outputs and load demands, the wheeling costs of sharing PV power are not constant. The purpose of determining the lowest wheeling charges is to indicate a suitable location for installing shared PV systems, as this represents least impact on LV network in terms of power losses. However, it should be noted that the allocation of wheeling cost to each customer depends on different types of solar sharing schemes (credit-based and power-based), which is another critical factor for the site-specific evaluation of wheeling costs.

It is acknowledged that wheeling costs for sharing PV power depend on the length of wheeled power passing and the amount of the shared PV power, but the key factor of sharing percentage (utilisation) of the LV distribution lines is likely to be more critical for the identification of wheeling charges than above mentioned two elements. Thus, this study proposes that sharing percentage can be used as an indicator for the evaluation of wheeling costs in utilising LV network for sharing PV power. Although the proposed study focuses on LV distribution systems, it can also be applicable to evaluate wheeling costs utilising medium voltage networks.

\section{REFERENCES}

[1] W.J. Lee, C.H Lin, L.D. Swift, "Wheeling Charge Under a Deregulated Environment", IEEE Trans. on Industry Applications, vol. 37, no. 1, pp. 178-183, Jan/Feb 2001.

[2] E. Langham, C. Cooper, N. Ison, "Virtual net metering in Australia: Opportunities and barriers". Report for Total Environment Centre, Institute for Sustainable Futures, 2013.

[3] SF Environment, City and County of San Francisco, "Virtual Net Energy Metering at Multitenant Buildings", http://www.sfenvironment.org/download/virtual-net-energymetering-at-multitenant-buildings, [Accessed Feb. 2013]
[4] A. Saxena, S.N. Pandey, L. Srivastava, "Genetic algorithm based wheeling prices allocation for Indian power utility by using MVA-mile and MW-mile approaches", Inter. Conf. on Emerging Trends in Electrical Electronics \& Sustainable Energy Systems (ICETEESES), PP.60-63, 2016.

[5] F. Li, N.P. Padhy, J. Wang, B. Kuri "MW+MVAr-Miles Based Distribution Charging Methodology", IEEE Power Engineering Society General Meeting, 2006.

[6] D. Avinash, B. Chalapathi, "MW-Mile method considering the cost of loss allocation for transmission pricing", Conf. on Power, Control, Communication and Computational Technologies for Sustainable Growth (PCCCTSG), pp. 128-131, 2015.

[7] D. Das, D. Divan, "Individual generator contributions towards loads and line flows in networks with loop flows", $41^{\text {st }}$ North American Power Symposium, pp. 1-6, 2009.

[8] J.W. Marangon Lima, "Allocation of transmission fixed charges: an overview", IEEE Trans. on Power Systems, vol. 11, no. 3, pp. 1409-1418, Aug. 1996

[9] D. Shirmohammadi, X.V. Filho, B. Gorenstin, M.V.P. Pereira, "Some fundamental technical concepts about cost based transmission pricing", IEEE Trans. on Power System, vol. 11, pp. 1002-1008, 1996.

[10] H. Happ "Cost of wheeling methodologies", IEEE Transactions on Power Systems, vol. 9 no. 1 pp. 147-156 1994.

[11] J. Pan, Y. Teklu, S. Rahman, "Review of usage-based transmission cost allocation methods under open access", IEEE Trans. on Power Systems, vol. 15, no. 1, pp. 1218-1224, 2000.

[12] N. Gu, X. Ling, Z. Hou, "A new approach for pricing of fixed costs in wheeling rates by modified mile-power method", Power System Technology, vol. 23, no. 2, pp. 66-68, 71, Feb. 1999

[13] J. Bialek, "Tracing the flow of electricity", IEE Proc. Generation Transmission and Distribution, vol. 143, no. 4, pp. 313-320, 1996.

[14] C.-T. Su, J.-H. Liaw, "Power wheeling pricing using power tracing and MVA-km method", IEEE Porto Power Tech Proc., 2001.

[15] Z. Ming, S. Liying, L. Gengyin, Y. Ni, "A novel power flow tracing approach considering power losses", IEEE Inter. Conf. on Electric Utility Deregulation, Restructuring and Power Technologies, vol. 1, no. 2, pp. 355-359, 2004.

[16] A. Tiwari, V. Ajjarapu, "Modified Methodology for Tracing Power Flow", IEEE Power Symposium, NAPS 2006, pp. 317322.

[17] D. Kirschen, R. Allan, G. Strbac, "Contributions of individual generators to loads and flows", IEEE Trans. on Power Systems, vol. 12, pp. 52-60, 1997

[18] K. Xie, C. Li, Y. Liu, "Tracing power flow from generators to loads and branches using incidence matrix multiplication", Power \& Energy Society General Meeting, 2009, pp.1-7.

[19] H. Sun, D. Yu, Q. Zheng, "AC power flow tracing in transmission networks", IEEE Power Engineering Society Winter Meeting, vol. 3, no. 1, pp. 1715-1720, 2000.

[20] J. Bialek, "Topological generation and load distribution factors for supplement charge allocation in transmission open access", IEEE Trans. on Power Systems, vol. 12, no. 3, pp. 1185-1193, Aug. 1997.

[21] Z. Jing, F. Wen, "Discussion on the Proving of Proportional Sharing Principle in Electricity Tracing Method", IEEE PES Transmission and Distribution Conf. and Exhibition: Asia and Pacific, pp. 1-5, 2005.

[22] Google Maps, "Smith St, Wollongong NSW 2500, Australia", https://www.google.com.au/maps, [Accessed Feb 2016].

[23] AS 60038-2012, Standard Voltages, Standards Australia. 